\title{
17 $\alpha$-Hydroxyprogesterone, 4-Androstenedione, and Testosterone Profiled by Routine Stable Isotope Dilution/Gas Chromatography-Mass Spectrometry in Plasma of Children
}

\author{
S. A. WUDY, U. A. WACHTER, J. HOMOKI, AND W. M. TELLER \\ Steroid Laboratory, First Department of Pediatrics, University of Ulm, D-89070 Ulm/Donau, \\ Federal Republic of Germany
} \begin{abstract}
ABST
Using stable isotope dilution/gas chromatography-mass spec-
trometry (ID/GC-MS), a physicochemical method, we have profiled the plasma steroids $17 \alpha$-hydroxyprogesterone, 4-androstenedione, and testosterone in normal children of various age groups. Comparison of our values with those obtained by direct immunologic assays and those using an extraction or purification step showed that immunoassays in general overestimate steroid concentrations. This was especially true for plasma samples in the neonatal period and was most expressed for the concentrations of $17 \alpha$-hydroxyprogesterone. Our study demonstrated the
\end{abstract}

applicability of ID/GC-MS to routine clinical steroid analysis. The application of ID/GC-MS is recommended whenever problems from matrix effects or cross-reactivity are likely to arise or suspicious results by immunoassays need to be rechecked. (Pediatr Res 38: 76-80, 1995)

\section{Abbreviation}

ID/GC-MS, isotope dilution/gas chromatography-mass spectrometry
Plasma $17 \alpha$-hydroxyprogesterone (17 $\alpha$-hydroxypregn-4ene-3,20-dione), 4-androstenedione (androst-4-ene-3,17dione), and testosterone (17 $\beta$-hydroxyandrost-4-en-3-one) are important parameters for the diagnosis and monitoring of hyperandrogenic disorders, most importantly 21 -hydroxylase deficiency (1). Currently, their routine determination is almost exclusively based on immunoassays. However, the reliability of steroid immunoassays was shown to be questionable when problems due to cross-reactivity or matrix effects are likely to arise (2-9).

To circumvent these problems, we have recently developed a method based on stable ID/GC-MS allowing the simultaneous determination of $17 \alpha$-hydroxyprogesterone, 4-androstenedione, and testosterone (10). It was the purpose of this study to obtain first mass spectrometric data on the plasma concentrations of these key steroids of androgen metabolism in children of various age groups and to further demonstrate the applicability of ID/GC-MS to clinical plasma steroid analysis.

Received August 3, 1994; accepted January 24, 1995.

Correspondence and reprint requests: Dr. Stefan A. Wudy, First Department of Pediatrics, University of Ulm, Prittwitzstr. 43, D-89070 Ulm/Donau, Federal Republic of Germany.

Supported by a grant from the Deutsche Forschungsgemeinschaft (to S.A.W.) (DFG Wu148/3).

\section{METHODS}

Subjects. We have analyzed plasma samples from 45 female and 48 male subjects. Infants and children were admitted for minor, non-endocrine disorders. Informed consent was obtained from their parents. Samples from adults were donated by staff members. The samples were collected between 0800 and $1000 \mathrm{~h}$. Furthermore, 20 umbilical cord blood specimens were collected from 10 female and 10 male full-term neonates born spontaneously after an uneventful pregnancy. All blood specimens were immediately centrifuged, and the plasma was stored at $-20^{\circ} \mathrm{C}$ until assay.

ID/GC-MS. Plasma 17 $\alpha$-hydroxyprogesterone, 4-androstenedione, and testosterone were determined in a single profile according to our own ID/GC-MS procedure (10). Deuteriumlabeled analogs of the steroids- $17 \alpha$-hydroxy-[11,11,12,12$\left.{ }^{2} \mathrm{H}_{4}\right]$ progesterone, $\left[7,7-{ }^{2} \mathrm{H}_{2}\right]$ androst-4-enedione, [16,16,17${ }^{2} \mathrm{H}_{3}$ ]testosterone-served as internal standards. Plasma $(0.5$ $\mathrm{mL}$ in male subjects, $0.5-2 \mathrm{~mL}$ in female subjects and children) was equilibrated with a cocktail containing the internal standards. After solvent extraction, the dried organic extracts were purified on Sephadex LH-20 minicolumns. Then, heptafluorobutyric acid derivatives were prepared, and a 0.1 aliquot of a processed plasma extract was analyzed. Gas chromatography was carried out on an OV-1 fused silica column (MachereyNagel, FRG; $25 \mathrm{~m} \times 0.15 \mathrm{~mm}$; film thickness $0.1 \mu \mathrm{m}$ ) housed 
in a DANI 6500 gas chromatograph. The gas chromatograph was directly interfaced to a Hewlett Packard 5970B mass selective detector operated in the selected ion monitoring mode. Quantitation was performed using the peak area ratios between the ion pairs of the analytes and their corresponding labeled analogs.

For the steroids studied, intra- and interassay coefficients of variation were between $3.5-4.1 \%$ and $3.8-3.9 \%$, respectively. Sensitivity was lowest for testosterone with a signal to noise ratio of 2.4 for $10 \mathrm{pg}$, and highest for $17 \alpha$-hydroxyprogesterone with a signal to noise ratio of 5.3 for $10 \mathrm{pg}$. Accuracy was determined by spiking plasma with known amounts of steroids. The agreement between the values found and the amounts added was excellent with a relative error less than $7.5 \%$. Standard plots were linear: 17 $\alpha$-hydroxyprogesterone, $y=$ $1.88 x+0.18, r=0.999 ; 4$-androstenedione, $y=1.37 x-0.24$, $r=0.997$; testosterone, $y=1.63 x-0.35, r=0.999(10)$.

RIA procedures. The umbilical cord plasma specimens were evaluated for concentrations of $17 \alpha$-hydroxyprogesterone, 4-androstenedione, and testosterone both by our ID/GC-MS method and commercially available direct RIA procedures. The latter were used without and with a previous ether extraction procedure. The direct RIA assays were performed on plasma aliquots of $200 \mu \mathrm{L}$ as described by the manufacturers using the ${ }^{125} \mathrm{I}-17 \alpha$-hydroxyprogesterone RIA kit from ICN Biomedicals (Costa Mesa, CA), the ${ }^{125}$ I-4-androstenedione RIA from Diagnostic System Laboratories (Webster, TX), and the ${ }^{125}$ I-testosterone RIA kit from Diagnostic Products Corporation (Bad Nauheim, FRG). Regarding the diethyl ether extraction, $200 \mu \mathrm{L}$ of plasma were extracted with $5 \mathrm{~mL}$ of diethyl ether by shaking vigorously for $5 \mathrm{~min}$. After freezing the aqueous phase, the supernatant was decanted and evaporated under flowing nitrogen. For assay, the sample was reconstituted in $0.5 \mathrm{~mL}$ of PBS.

\section{RESULTS}

Application of our assay in a clinical setting is demonstrated by two examples of typical ion chromatograms: Figure 1 shows the steroid profile of an infant in whom 21-hydroxylase deficiency could be excluded. In another patient, a newborn, elevated $17 \alpha$-hydroxyprogesterone could confirm 21hydroxylase deficiency (Fig. 2).

The concentrations of plasma $17 \alpha$-hydroxyprogesterone, 4-androstenedione, and testosterone determined by ID/GC-MS in normal subjects of various age groups are summarized in Tables $1-3$.

$17 \alpha$-Hydroxyprogesterone, 4-androstenedione, and testosterone were assayed by ID/GC-MS and direct RIA with and without ether extraction in 20 samples of cord plasma. A comparison between the results produced by the different techniques is presented in Figure 3. The steroid values produced by ID/GC-MS were the lowest with the narrowest range. Direct RIA led to higher and more scattering steroid values. Ether extraction led to less scattering for all three hormones analyzed. A decrease in absolute steroid levels after ether extraction was noted only for 4-androstenedione and testosterone, whereas the mean levels of $17 \alpha$-hydroxyprogesterone remained practically unchanged.

\section{DISCUSSION}

Currently, analytical methods based on mass spectrometry present the most specific quantitative methods for steroid determination $(11,12)$. In contrast to immunoassays, a physicochemical method such as ID/GC-MS is independent of phenomena such as cross-reactivity or matrix effects. Stable isotope-labeled analogs (13) are ideally suited as internal standards because they show similar chemical behavior and offer the advantage of compensation for losses of analyte during the workup procedure. They further avoid radioactive contamination of personnel and instrumentation. Gas chromatography bears the greatest potential in determining a whole spectrum of steroid hormones simultaneously in a single "profile," whereas RIA allow only the measurement of a single steroid at a time.

For the first time, basal plasma levels of $17 \alpha$-hydroxyprogesterone, 4-androstenedione, and testosterone have been profiled by ID/GC-MS in normal female and male subjects at
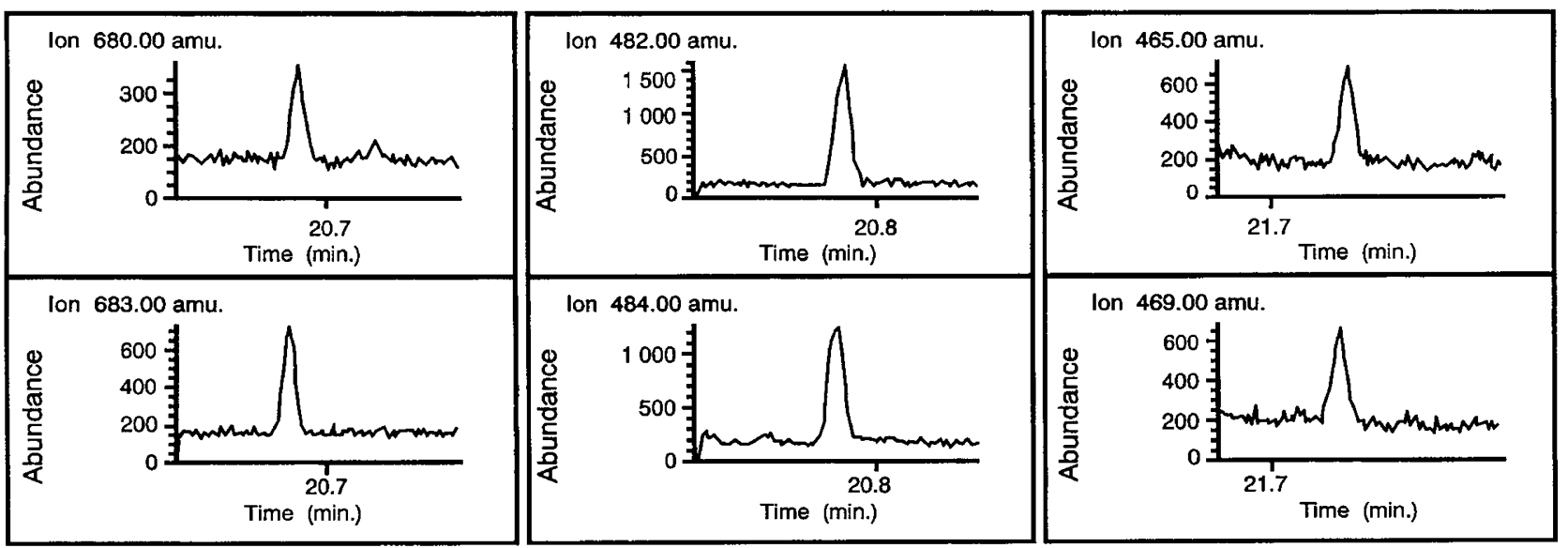

Figure 1. Exclusion of 21-hydroxylase deficiency in a 2-mo-old boy. Selected ion recording of a 0.1 aliquot of a processed extract of $0.5 \mathrm{~mL}$ of plasma. Each box contains the ion traces of typical corresponding fragments of a particular analyte (upper half) and its internal standard (lower half). Testosterone ( $\mathrm{m} / \mathrm{z} 680$, $\mathrm{m} / \mathrm{z} 683): 3.74 \mathrm{nmol} / \mathrm{L} ; 4$-androstenedione $(\mathrm{m} / \mathrm{z} 482, \mathrm{~m} / \mathrm{z} 484): 4.19 \mathrm{nmol} / \mathrm{L} ; 17 \alpha$-hydroxyprogesterone $(\mathrm{m} / \mathrm{z} 465, \mathrm{~m} / \mathrm{z} 469): 2.42 \mathrm{nmol} / \mathrm{L}$. 


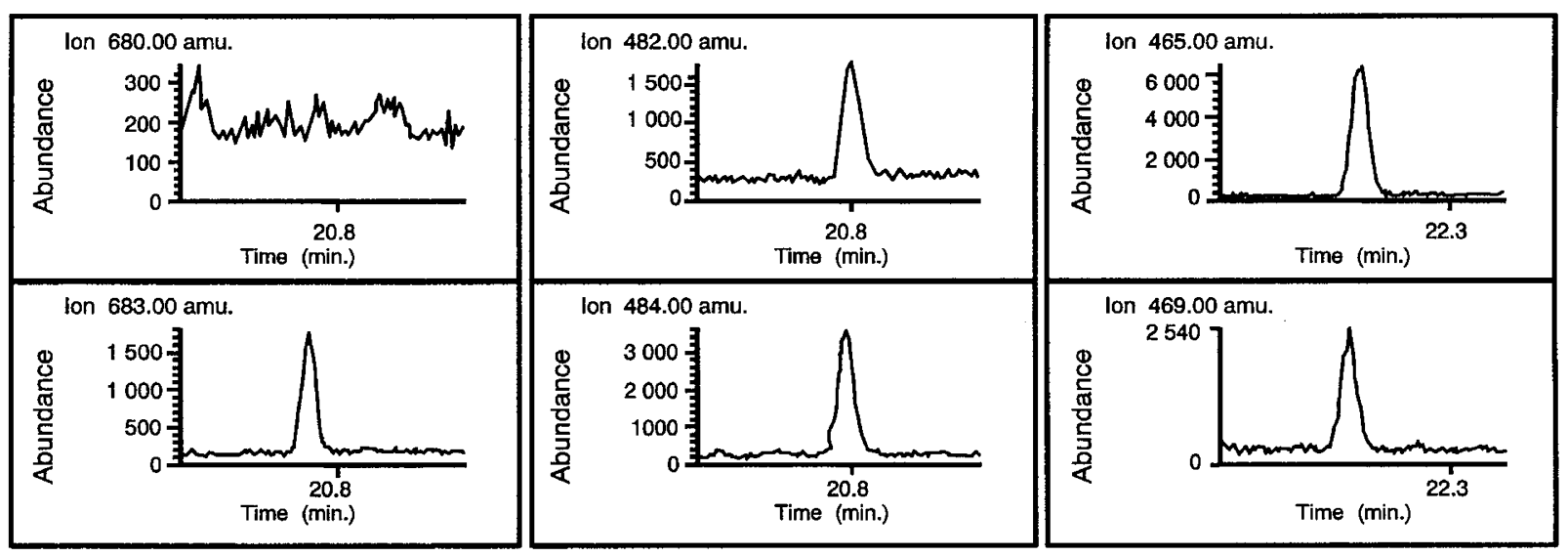

Figure 2. Diagnosis of 21-hydroxylase deficiency in a 3-d-old female patient with virilized genitalia. Selected ion recording of a 0.1 aliquot of a processed extract of $0.1 \mathrm{~mL}$ of plasma. Testosterone ( $\mathrm{m} / \mathrm{z} 680, \mathrm{~m} / \mathrm{z} 683)$ not detected; 4-androstenedione (m/z 482, m/z 484): $15.65 \mathrm{nmol} / \mathrm{L} ; 17 \alpha$-hydroxyprogesterone (m/z $465, \mathrm{~m} / \mathrm{z} 469): 66.81 \mathrm{nmol} / \mathrm{L}$.

Table 1. Concentrations of plasma $17 \alpha$-hydroxyprogesterone $(\mathrm{nmol} / \mathrm{L})$ determined by $I D / G C$-MS in normal female and male subjects

\begin{tabular}{|c|c|c|c|c|c|c|}
\hline \multirow[b]{2}{*}{ Age } & \multicolumn{3}{|c|}{ Female subjects } & \multicolumn{3}{|c|}{ Male subjects } \\
\hline & $n$ & Mean \pm SD & Range & $n$ & Mean $\pm S D$ & Range \\
\hline Cord plasma & 10 & $15.34 \pm 11.83$ & $6.74-43.69$ & 10 & $15.97 \pm 7.98$ & $5.65-32.13$ \\
\hline $1-4 \mathrm{wk}$ & 6 & $2.11 \pm 0.99$ & $1.21-4.08$ & 8 & $3.23 \pm 1.48$ & $1.27-6.20$ \\
\hline $2-12 \mathrm{mo}$ & 4 & $1.75 \pm 1.87$ & $<$ d.1. ${ }^{*}-2.48$ & 4 & $2.14 \pm 0.66$ & $1.42-2.90$ \\
\hline $2-6 y$ & 7 & $0.48 \pm 0.30$ & $0.15-0.96$ & 7 & $0.27 \pm 0.15$ & $0.18-0.54$ \\
\hline $7-10 y$ & 9 & $0.75 \pm 0.60$ & $0.36-1.99$ & 8 & $0.75 \pm 0.57$ & $0.39-1.66$ \\
\hline $11-15$ y & 9 & $1.27 \pm 0.60$ & $0.81-1.75$ & 11 & $1.48 \pm 0.69$ & $0.42-2.29$ \\
\hline$>16 y$ & 10 & $1.45 \pm 0.75$ & $0.69-2.54$ & 10 & $3.29 \pm 1.36$ & $1.54-5.56$ \\
\hline
\end{tabular}

Note: To convert $17 \alpha$-hydroxyprogesterone concentrations from $\mathrm{nmol} / \mathrm{L}$ to $\mathrm{ng} / \mathrm{dL}$, multiply by 33.1 .

$*<$ d.l., below limit of detection.

Table 2. Concentrations of plasma 4-androstenedione (nmol/L) determined by ID/GC-MS in normal female and male subjects

\begin{tabular}{|c|c|c|c|c|c|c|}
\hline \multirow[b]{2}{*}{ Age } & \multicolumn{3}{|c|}{ Female subjects } & \multicolumn{3}{|c|}{ Male subjects } \\
\hline & $n$ & Mean $\pm \mathrm{SD}$ & Range & $n$ & Mean $\pm \mathrm{SD}$ & Range \\
\hline Cord plasma & 10 & $7.58 \pm 3.42$ & $4.02-14.47$ & 10 & $8.18 \pm 1.18$ & $5.13-9.30$ \\
\hline $1-4 \mathrm{wk}$ & 6 & $5.76 \pm 1.60$ & $1.22-6.25$ & 8 & $3.91 \pm 1.22$ & $0.73-4.82$ \\
\hline $2-12 \mathrm{mo}$ & 4 & $2.37 \pm 1.60$ & $0.38-4.37$ & 4 & $2.79 \pm 1.15$ & $0.97-3.84$ \\
\hline $2-6 y$ & 7 & $0.70 \pm 0.28$ & $0.25-1.01$ & 7 & $0.09 \pm 0.04$ & $0.04-0.15$ \\
\hline $7-10 y$ & 9 & $1.08 \pm 0.66$ & $0.53-2.10$ & 8 & $0.19 \pm 0.08$ & $0.13-0.32$ \\
\hline $11-15 y$ & 9 & $4.16 \pm 1.08$ & $2.94-5.74$ & 11 & $0.57 \pm 0.35$ & $0.29-1.39$ \\
\hline$>16 y$ & 10 & $4.72 \pm 2.65$ & $2.24-10.49$ & 10 & $1.13 \pm 0.28$ & $0.64-1.45$ \\
\hline
\end{tabular}

Note: To convert 4-androstenedione concentrations from $\mathrm{nmol} / \mathrm{L}$ to $\mathrm{ng} / \mathrm{dL}$ multiply by 28.6 .

different ages. Our data inform about the actual hormonal concentrations and illustrate that commercial direct RIA can substantially overestimate the true steroid values.

Regarding $17 \alpha$-hydroxyprogesterone, the most striking differences between our values and those determined by immunologic methods were found in cord plasma. Widely divergent plasma levels have so far been published (14-20). Using direct RIA, values as high as $203 \pm 37.8 \mathrm{nmol} / \mathrm{L}$ (mean $\pm \mathrm{SD}$ ) in boys and $184 \pm 34.5 \mathrm{nmol} / \mathrm{L}$ in girls have been reported (16). Values of comparable order were obtained using our in-house direct RIA (Fig. 3). RIA procedures using an additional purification step such as Celite chromatography led to much lower values: $92.7 \pm 40.9 \mathrm{nmol} / \mathrm{L}$ in female subjects and $56.4 \pm 30.7$ $\mathrm{nmol} / \mathrm{L}$ in male subjects (14). The values determined by ID/ GC-MS were even 4-6 times lower than the latter and did not show any significant sex difference (Table 1). Concerning the other age groups, the $17 \alpha$-hydroxyprogesterone concentrations determined by ID/GC-MS were generally up to 2 times lower than those determined by RIA techniques using a chromatographic step $(14,17,21,22)$.

After an intense debate on the reliability of $17 \alpha$ hydroxyprogesterone determined by direct RIA in the neonatal period and early infancy $(9,23-27)$, it could meanwhile be demonstrated that the interference of steroid monosulfates from the fetal adrenal zone, mainly $17 \alpha$-hydroxypregnenolone sulfate, can lead to false positively elevated $17 \alpha$-hydroxyprogesterone levels (28). The production of steroid sulfates in the fetal adrenal zone lasts well into infancy (29).

Our determinations of $17 \alpha$-hydroxyprogesterone in umbilical cord plasma by direct RIA showed that $17 \alpha$-hydroxypro- 
Table 3. Concentrations of plasma testosterone (nmol/L) determined by ID/GC-MS in normal female and male subjects

\begin{tabular}{|c|c|c|c|c|c|c|}
\hline \multirow[b]{2}{*}{ Age } & \multicolumn{3}{|c|}{ Female subjects } & \multicolumn{3}{|c|}{ Male subjects } \\
\hline & $n$ & Mean $\pm \mathrm{SD}$ & Range & $n$ & Mean $\pm \mathrm{SD}$ & Range \\
\hline Cord plasma & 10 & $0.27 \pm 0.17$ & $0.10-0.65$ & 10 & $0.93 \pm 0.24$ & $0.45-1.25$ \\
\hline $1-4 \mathrm{wk}$ & 6 & $<$ d.1.* & & 8 & $8.19 \pm 7.77$ & $0.55-20.06$ \\
\hline $2-12 \mathrm{mo}$ & 4 & $<$ d.l. & & 4 & $2.46 \pm 1.59$ & $<$ d.1.-4.61 \\
\hline $2-6 y$ & 7 & $0.14 \pm 0.04$ & $0.07-0.28$ & 7 & $0.18 \pm 0.04$ & $0.04-0.24$ \\
\hline $7-10 y$ & 9 & $0.45 \pm 0.17$ & $0.21-0.66$ & 8 & $0.28 \pm 0.14$ & $0.10-0.59$ \\
\hline $11-15 y$ & 9 & $0.80 \pm 0.10$ & $0.69-0.97$ & 11 & $7.15 \pm 6.49$ & $0.24-16.35$ \\
\hline$>16 y$ & 10 & $0.94 \pm 0.10$ & $0.31-2.26$ & 10 & $17.74 \pm 4.27$ & $13.26-26.04$ \\
\hline
\end{tabular}

Note: To convert testosterone concentrations from $\mathrm{nmol} / \mathrm{L}$ to $\mathrm{ng} / \mathrm{dL}$, multiply by 28.8 .

$*<$ d.l., below limit of detection.
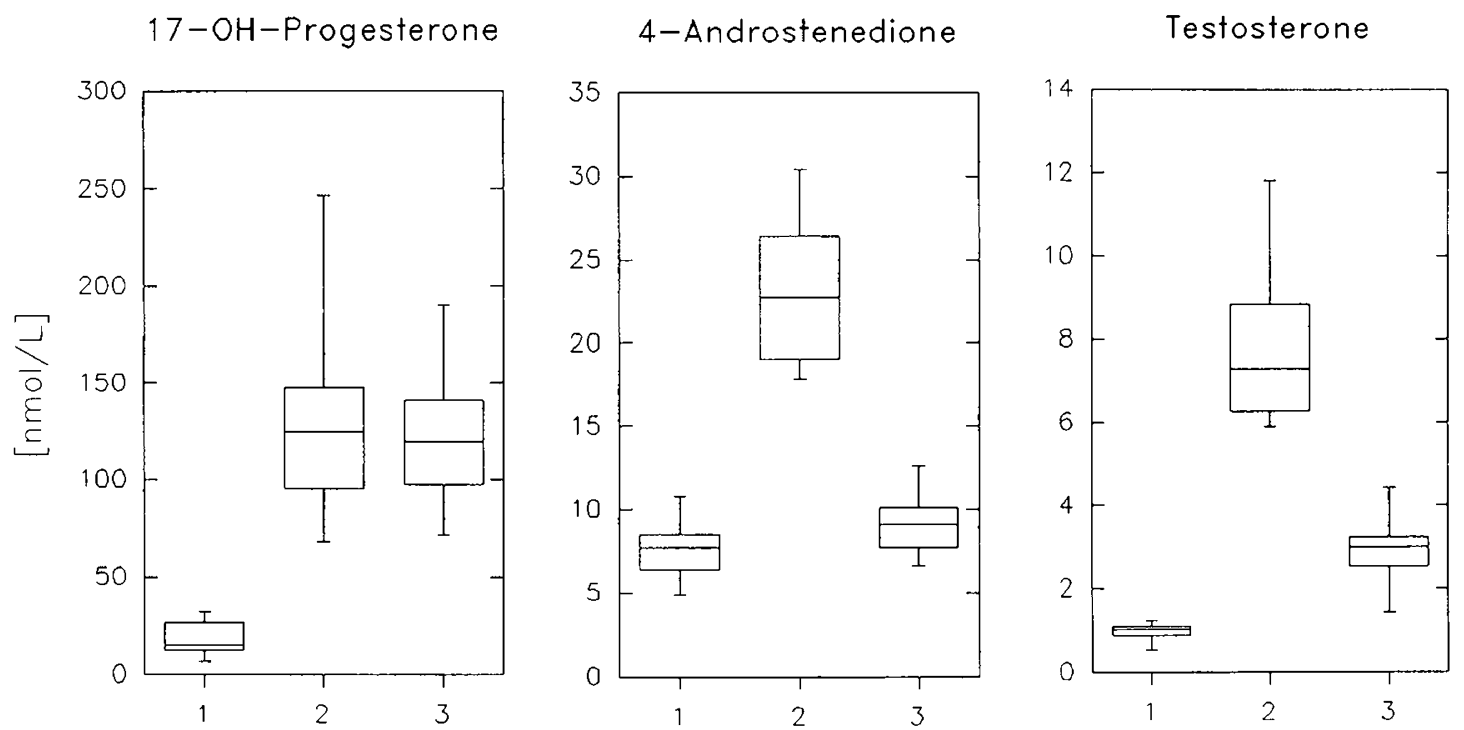

Figure 3. Determination of 17-hydroxyprogesterone, 4-androstenedione, and testosterone in cord plasma from 10 male and 10 female neonates by ID/GC-MS (1), direct RIA (2), and direct RIA after ether extraction (3). Boxes mark 25th, 50th, 75th, and end of bars 10 th and 90 th centiles.

gesterone values hardly decreased after ether extraction (Fig. 3). We conclude that an additional extraction step does not necessarily improve the diagnostic efficiency of a direct assay. As mentioned before, even inclusion of chromatographic steps can obviously not eliminate all interferences in neonatal samples. These findings bear importance regarding screening programs for 21-hydroxylase deficiency, where, for reasons of practicability, direct immunologic procedures are advantageous but are likely to produce false positively elevated results.

In the case of 4-androstenedione, ID/GC-MS could not confirm the concentrations found in cord plasma using specific RIA with Celite chromatography (30). Inexplicably, the values found by ID/GC-MS (Table 2) were 2-3 times higher than the RIA values (female subjects, $3.3 \pm 1.30 \mathrm{nmol} / \mathrm{L}$; male subjects, $3.0 \pm 0.98 \mathrm{nmol} / \mathrm{L})$. In our experiments, direct RIA led to an overestimation of 4-androstenedione in cord blood (Fig. 3 ). This tendency was less expressed as in the case of $17 \alpha$ hydroxyprogesterone. The interfering factor still remains to be determined. Unlike $17 \alpha$-hydroxyprogesterone, ether extraction could reduce almost all interferences. In later stages of life, no substantial differences to other series were evident $(22,30)$.

Concerning testosterone in cord plasma, the values produced by ID/GC-MS showed a much more marked sex difference than has been previously assumed (30). Again, analysis by direct RIA resulted in marked overestimation, which partially could be reduced after ether extraction (Fig. 3). In the neonatal period, our values for males corresponded with those that have already been published (30). In female neonates, however, testosterone was undetectable by our method. Concerning later life, no gross differences to other series could be found $(22$, 30).

The problems of lacking specificity and consecutive overestimation of true steroid values by immunologic methods, especially direct assays, is of particular importance not only in the newborn period and early infancy. Problems with steroid immunoassays have further been reported in prepuberty (3), in female samples $(4,5,7)$, in pregnancy $(4)$, in disorders of steroidogenesis $(6,31,32)$, or when analyzing different media, e.g. ovarian follicular fluid (2). ID/GC-MS could help circumvent these analytical problems. If the technique was used in different studies, comparability between data would not present a problem because no individual reference ranges would be needed for each immunoassay (6).

The potential of ID/GC-MS in quantitative plasma steroid analysis has not yet been exploited to its full extent. So far, ID/GC-MS has found application as a reference methodology presenting the "gold standard" for the evaluation of steroid immunoassays (12). Its use as a routine method has been lacking, however. Drawbacks concerning the use of ID/ GC-MS in a clinical setting have primarily been the huge costs 
of the sophisticated instrumentation, complex workup procedures, and the unavailability of most stable isotope-labeled internal standards. However, during the last decade, vast technical improvements have rendered the development of reliable labor and cost effective GC/MS instruments possible. With respect to appropriate internal standards, several suitable pathways leading to nonradioactive internal standards have meanwhile been published (13).

We have recently developed an ID/GC-MS method for the profiling of $17 \alpha$-hydroxyprogesterone, 4 -androstenedione, and testosterone which we believe to be clinically applicable. Our method allows "day-return" reporting of results. Sample preparation is simple and can be completed within $6 \mathrm{~h}$. Up to 20 specimens can conveniently be prepared in parallel, and up to 20 samples can be analyzed per day on a single GC/MS instrument (10). Of course, regarding the possible number of samples to be analyzed, GC/MS cannot compete with direct immunoassays because the latter techniques require only minimal sample preparation and allow analysis of numerous samples in batch assays in contrast to only serial assays possible with GC/MS.

We therefore suggest to set up priorities for steroid analysis by ID/GC-MS. Thus, a small number of specialized laboratories equipped with the analytical instrumentation and expertise should suffice. Our ID/GC-MS assay could be applied to the analysis of plasma from neonates or young infants suspected of 21-hydroxylase deficiency. Another field of application would be the prenatal diagnosis of 21-hydroxylase deficiency from amniotic fluid. Simultaneous measurement of $17 \alpha$-hydroxyprogesterone, 4-androstenedione, and testosterone in amniotic fluid is advantageous in detecting the sex of fetuses (33) and all cases of 21-hydroxylase deficiency (34). We recently demonstrated (35) that reliable steroid analysis still remains a pillar of pre- and postnatal diagnosis of 21-hydroxylase deficiency in case no index patient is available.

To conclude, plasma steroid analysis by ID/GC-MS will not replace immunoassays in general. Besides its role as a reference methodology, we suggest application of ID/GC-MS in a clinical setting whenever problems from matrix effects or cross-reactivity are likely to arise or suspicious results by immunoassays need to be rechecked.

Acknowledgment. The authors thank Dr. R. Benz (Endocrine Laboratory, Department of Obstetrics and Gynecology, University of Ulm) for the RIA determinations of $17 \alpha$ hydroxyprogesterone, 4-androstenedione, and testosterone.

\section{REFERENCES}

1. New MI, White PC, Pang S, Dupont B, Speiser PW 1989 The adrenal hyperplasias. In: Scriver CR, Beaudet AL, Sly WS, Valle D (eds) The Metabolic Basis of Inherited Disease. McGraw-Hill, New York, pp 1881-1917

2. Silberzahn P, Dehennin L, Zwain I, Reiffsteck A 1985 Gas chromatography mass spectrometry of androgens in eqine ovarian follicles at ultrastructurally defined stages of development. Identification of 19-nortestosterone in follicular fluid. Endocrinology 117:2176-2181

3. Belgorosky A, Rivarola MA 1987 Changes in serum sex hormone-binding globulin and in serum non-sex hormone-binding globulin-bound testosterone during prepuberty in boys. J Steroid Biochem 27:291-295

4. Slaats EH, Kennedy JC, Kruijswijk H 1987 Interference of sex-hormone binding globulin in the 'coat-a-count' testosterone no-extraction radionimmunoassays. Clin Chem 33:300-302
5. Wheeler MJ 1987 Warning on serum testosterone measurement. Lancet 2:514

6. Chasalow FI, Blethen SI, Ducket D, Zeitlin S, Greenfield J 1989 Serum levels of DHA-S as determined by commercial kits and reagents. Steroids 54:373-383

7. Masters AM, Hahnel R 1989 Investigation of sex-hormone binding globulin interference in direct radioimmunoassays for testosterone and oestradiol. Clin Chem 35:979-984

8. Lee A, Ellis G 1991 Serum $17 \alpha$-hydroxyprogesterone in infants and children as measured by a direct radioimmunoassay kit. Clin Biochem 24:505-511

9. Wallace AM, Beastall GH 1991 Direct assays for adrenal steroids in neonates. Ann Clin Biochem 28:113

10. Wudy SA, Wachter UA, Homoki J, Teller WM, Shackleton CHL 1992 Androgen metabolism assessment by routine gas chromatography/mass spectrometry profiling of plasma steroids: Part 1, unconjugated steroids. Steroids 57:319-324

11. Shackleton CHL 1985 Mass spectrometry: Application to steroid and peptide research. Endocr Rev 6:441-486

12. Siekmann L 1979 Determination of steroid hormones by the use of isotope dilutionmass-spectrometry: A definitive method in clinical chemistry. J Steroid Biochem $11: 117-123$

13. Wudy SA 1990 Synthetic procedures for the preparation of deuterium labeled analogs of naturally occuring steroids. Steroids 55:463-471

14. Forest MG, Cathiard AM 1978 Ontogenetic study of plasma $17 \alpha$-hydroxyprogesterone in the human. I. Postnatal period: Evidence for a transient ovarian activity in infancy. Pediatr Res 12:6-11

15. Sippell WG, Becker H, Versmold HT, Bidlingmaier F, Knorr D 1978 Longitudinal studies of plasma aldosterone, corticosterone, deoxycorticosterone, progesterone, 17-hydroxyprogesterone, cortisol, and cortisone determined simultaneously in mother and child at birth and during the early neonatal period. I. Spontaneous delivery. J Clin Endocrinol Metab 46:971-985

16. Hughes IA, Riad-Fahmy D, Griffiths K 1979 Plasma 17OH-Progesterone concentrations in newborn infants. Arch Dis Child 54:347-349

17. Schnakenburg K, Bidlingmaier F, Knorr D 1980 17-Hydroxyprogesterone, androstenedione, and testosterone in normal children and in prepubertal patients with congenital adrenal hyperplasia. Eur J Pediatr 133:259-267

18. Godo B, Visser HKA, Degenhart HJ 1981 Plasma 17-OH-Progesterone in fullterm and preterm infants at birth and during the early neonatal period. Horm Res 15:65-71

19. Murphy JF, Joyce BG, Dyas J, Hughes IA 1983 Plasma 17-hydroxyprogesterone concentrations in ill newborn infants. Arch Dis Child 58:532-534

20. Wiener D, Smith J, Dahlem S, Berg G, Moshang T 1987 Serum adrenal steroid levels in healthy full-term 3-day-old infants. J Pediatr 110:122-124

21. Sippell WG, Dörr HG, Bidlingmaier F, Knorr D 1980 Plasma levels of aldosterone, corticosterone, 11-deoxycorticosterone, cortisol, and cortisone during infancy and childhood. Pediatr Res 14:39-46

22. Lashansky G, Saenger P, Fishman K, Gautier T, Mayes D, Berg G 1991 Normative data for adrenal steroidogenesis in a healthy pediatric population: age- and sexrelated changes after adrenocorticotropin stimulation. J Clin Endocrinol Metab 73:674-686

23. Read GF, Walker RF, Ford P, Riad-Fahmy D 1990 External quality assessment in small schemes: the case of 17- $\alpha$-hydroxyprogesterone. Ann Clin Biochem 27:276278

24. Bodlaender P 1991 Direct assays for adrenal steroids in neonates. Ann Clin Biochem 28:422-423

25. Honour JW, Brook CGD 1991 Boy or girl? Ann Clin Biochem 28:421-422

26. Honour JW, Rumsby G 1993 Problems in diagnosis and management of congenital adrenal hyperplasia due to 21-hydroxylase deficiency. J Steroid Biochem Mol Biol 45:69-74

27. Makela SK, Ellis G 1988 Nonspecificity of a direct $17 \alpha$-hydroxyprogesterone radioimmunoassay kit when used with samples from neonates. Clin Chem 34:2070-2075

28. Wong T, Shackleton CHL, Covey TR, Ellis G 1992 Identification of steroids in neonatal plasma that interfere with $17 \alpha$-hydroxyprogesterone radioimmunoassays. Clin Chem 38:1830-1837

29. Shackleton CHL 1984 Steroid synthesis and catabolism in the fetus and neonate. In: Makin HLF (ed) Biochemistry of Steroid Hormones, Ed. 2. Blackwell, London, pp 441-477

30. Forest MG 1989 Physiological changes in circulating androgens. In: Forest MG (ed) Androgens in Childhood. Karger, Basel, pp 104-129

31. Shackleton CHL, Kletke C, Wudy S, Pratt JH 1990 Dehydroepiandrosterone sulfate quantification in serum using high-performance liquid chromatography/mass spectrometry and a deuterated internal standard: A technique suitable for routine use or as a reference method. Steroids 55:472-478

32. Wudy SA, Wachter UA, Homoki J, Teller WM 1993 Determination of dehydroepiandrosterone sulfate in human plasma by gas chromatography/mass spectrometry using a deuterated internal standard: A method suitable for routine clinical use. Horm Res 39:235-240

33. Forest MG, Betuel H, Couillin P, Boue A 1981 Prenatal diagnosis of congenital adrenal hyperplasia (CAH) due to 21-hydroxylase deficiency by steroid analysis in the amniotic fluid of mid-pregnancy: Comparison with HLA typing in 17 pregnancies at risk for CAH. Prenatal Diagn 1:197-207

34. Dörr HG, Sippell WG 1992 Prenatal dexamethasone treatment in pregnancies at risk for congenital adrenal hyperplasia due to 21-hydroxylase deficiency: effect on midgestational amniotic fluid steroid levels. J Clin Endocrinol Metab 76:117-120

35. Wudy SA, Homoki J, Teller WM 1994 Successful prenatal treatment of congenital adrenal hyperplasia due to 21-hydroxylase deficiency. Eur J Pediatr 153:556-559 